УДК 343.114

12.00.00 Юридические науки

ОБСТОЯТЕЛЬСТВА, ВЛИЯЮЩИЕ НА СРОКИ И КАЧЕСТВО РАССМОТРЕНИЯ УГОЛОВНЫХ ДЕЛ В СУДАХ АПЕЛЛЯЦИОННОЙ ИНСТАНЦИИ

Душа Виталий Владимирович аспирант кафедры уголовного процесса ФГБОУ ВО «Кубанский государственный аграрный университет имени И.Т. Трубилина», Краснодар, Россия

В настоящей статье проводится анализ сущности системы обжалования, проверки и пересмотра судебных решений; определяется состояние данной системы и её функционирование на основе современных тенденций развития действующего уголовно-процессуального законодательства, практики его применения; выявляются обстоятельства и коллизии, влияющие на сроки и качество рассмотрения уголовных дел в судах апелляционной инстанции, а также формулируются рекомендации и предложения по совершенствованию работы судов апелляционной инстанции

Ключевые слова: УГОЛОВНЫЙ ПРОЦЕСС, УГОЛОВНОЕ СУДОПРОИЗВОДСТВО,

УГОЛОВНО-ПРОЦЕССУАЛЬНЫЙ ЗАКОН, ВЕРХОВНЫЙ СУД, ОКРУЖНЫЕ СУДЫ,

СУД ПЕРВОЙ ИНСТАНЦИИ,

АПЕЛЛЯЦИОННАЯ ИНСТАНЦИЯ,

АПЕЛЛЯЦИОННАЯ ЖАЛОБА,

АПЕЛЛЯЦИОННАЯ ПРОВЕРКА,

КАССАЦИОННАЯ ИНСТАНЦИЯ, СУДЕБНАЯ

ЗАЩИТА, ХОДАТАЙСТВО, ОБЖАЛОВАНИЕ, ПРОВЕРКА, ПЕРЕСМОТР, ИССЛЕДОВАНИЕ ДОКАЗАТЕЛЬСТВ, КОЛЛИЗИИ, СУДЕБНАЯ ПРАКТИКА, РЕФОРМА, НАУЧНЫЕ ТРУДЫ
UDC 343.114

Legal sciences

\section{CIRCUMSTANCES AFFECTING THE TIMING AND QUALITY CONSIDERATION OF CRIMINAL CASES IN THE COURTS OF APPEAL}

Dusha Vitaliy Vladimirovich

Postgraduate of the Department of criminal process FSBEI HE «Kuban state agrarian university named after I. T. Trubilin», Krasnodar, Russia

In the present article the analysis of essence of system of the appeal, check and revision of judgments is carried out; the state is defined the condition of this system and its functioning on the basis of current trends of development of the acting criminal procedure legislation, practice of its application is defined; the circumstances and collisions influencing terms and quality of consideration of criminal cases in courts of appeal instance come to light and also recommendations and suggestions for improvement of work of the courts of the court of appeal are formulated

Keywords: CRIMINAL PROCESS, CRIMINAL TRIAL, CRIMINAL PROCEDURE LAW, SUPREME COURT, DISTRICT COURTS, COURT OF FIRST INSTANCE, APPELLATE INSTANCE, PETITION FOR APPEAL, APPEAL CHECK, CASSATION INSTANCE, JUDICIAL PROTECTION, PETITION, APPEAL, CHECK, REVIEW, RESEARCH OF PROOFS, COLLISIONS, COURT PRACTICE, REFORM, SCIENTIFIC WORKS

Doi: 10.21515/1990-4665-125-045

Проблемы обжалования, проверки и пересмотра судебных решений всегда находились в центре внимания учёных-процессуалистов. В первом десятилетии XXI века интерес к вышеуказанным проблемам значительно усилился. Данный факт подтверждается регулярным научным обсуждением и дальнейшим введением в УПК РФ новых положений, предусматривающих изменения, в частности, в апелляционной инстанции. Научные труды большинства авторов, изучающих данную проблематику, представ- 
ляют научную ценность, но их работы преимущественно направлены на изучение обжалования, проверки и пересмотра судебных решений в рамках норм, закреплённых законодательством. Признавая несомненную значимость научных разработок в сфере вышеобозначенной проблематики, можно отметить, что в уголовно-процессуальной науке необходим чёткий системный подход для достижения цели, выраженной в дальнейшем совершенствовании уголовно-процессуального законодательства, в том числе, в части устранения обстоятельств и коллизий, влияющих на сроки и качество рассмотрения уголовных дел в судах апелляционной инстанции.

Цель настоящей статьи - проанализировать сущность системы обжалования, проверки и пересмотра судебных решений; определить состояние данной системы и её функционирование на основе современных тенденций развития действующего уголовно-процессуального законодательства, практики его применения; выявить обстоятельства и коллизии, влияющие на сроки и качество рассмотрения уголовных дел в судах апелляционной инстанции, а также сформулировать рекомендации и предложения по совершенствованию работы судов апелляционной инстанции. Понятно, что рамки настоящей статьи не позволяют дать полный анализ всего круга проблем, сказывающихся на оперативности исследуемой формы судебной защиты, тем не менее, остановимся на некоторых вопросах и постараемся их рассмотреть.

1 января 2017 года исполнилось 4 года, как в уголовном судопроизводстве России в полном объёме функционирует новый апелляционный и кассационный порядок проверки вынесенных судебных решений, введённый Федеральным законом № 433-Ф3 [1].

За данный период в ходе судебной практики накопилось немало проблем, связанных с обстоятельствами, влияющими на процедуру и длительность проверки судебных решений в вышеуказанных инстанциях, в частности, в апелляционной. 
Апелляционные жалобы и представления на приговор или иное судебное решение суда первой инстанции в уголовном процессе подаются письменно в суд первой инстанции не позднее 10 суток со дня их вынесения, а осужденным, содержащимся под стражей, - в тот же срок со дня вручения ему копии приговора, определения, постановлении (ч. 1 ст. 389. 4 УПК РФ). Данный срок не в полной мере соответствует реальным срокам, которые необходимы для подачи жалобы или представления. Перед составлением апелляционной жалобы участник уголовного судопроизводства вынужден, как правило, неоднократно обращаться в суд для ознакомления с протоколом и приговором, с жалобами других участников и представлением прокурора, на что уходит определенное время.

Во-первых, в соответствии со ст. 312 УПК РФ суд обязан в течение 5 суток со дня провозглашения приговора вручить осужденному или оправданному, его защитнику, обвинителю, потерпевшему, гражданскому истцу, гражданскому ответчику и им представителям копию приговора. Вовторых, в течение 3 суток со дня окончания судебного разбирательства протокол судебного заседания должен быть изготовлен и подписан председательствующим и секретарём (ч. 6 ст. 259 УПК РФ). Но на практике не всегда своевременно изготавливается протокол судебного заседания и вручается копия приговора. Кроме того, уголовно-процессуальный закон предоставляет право сторонам подавать замечания на протокол судебного заседания в течение 3 суток со дня ознакомления (ч. 1 ст. 260 УПК РФ). Эти замечания должны быть рассмотрены председательствующим незамедлительно. Но на их рассмотрение также требуется определенное время, которое законом не установлено. Поэтому, зачастую, когда на протокол подаются замечания, их рассмотрение фактически охватывает весь 10дневный срок, а иногда бывает и его недостаточно.

Отдельно остановимся на коллизиях, возникающих в вопросе об оперативности апелляционной проверки, где одной из наиболее обсуждаемых 
проблем нового апелляционного производства являлся отказ Верховного суда от создания системы окружных апелляционных судов, призванных обеспечить реальную оперативность апелляционной судебной защиты. Чрезмерная территориальная удалённость судов апелляционной инстанции, видимо, до конца 2016 года не являлась определяющей для обеспечения необходимой оперативности апелляционной судебной защиты. В настоящий момент Верховный суд инициировал реформу судоустройства. Председатель Верховного суда Вячеслав Лебедев предложил одну из самых серьезных реформ судопроизводства за время своего пребывания в должности.

В ноябре 2016 года Верховный суд выступил с инициативой создания в системе общей юрисдикции отдельных апелляционных и кассационных судов по аналогии с действующей системой арбитражных судов, которая хорошо себя зарекомендовала: «Это будут самостоятельные инстанции, сформированные в специально учреждённых округах, не совпадающих с административно-территориальным делением. Такое нововведение позволит повысить независимость судебных решений и унифицировать систему судоустройства, обещает Лебедев. Верховный суд планирует обсудить эту инициативу на IX съезде судей, который запланирован на конец года» [3].

Сейчас апелляционной инстанцией для районных судов являются Верховные суды республик, краевые, областные суды, суды городов федерального значения, суд автономной области, суды автономных округов, а кассационные жалобы подают уже в Верховный суд. Решения вышеперечисленных судов проверяет судебная коллегия Верховного суда, а вот полноценной кассации для них, по сути, не существует. Создание системы окружных апелляционных и окружных кассационных судов позволит получить полноценную двухуровневую систему проверки в том числе и решений региональных судов. Проверкой решений районных судов будет заниматься не региональный суд, а апелляционная инстанция. Это позволит 
снизить влияние административного ресурса: за судами субъектов РФ сохранится довольно ограниченная категория дел, поэтому их штат можно будет перераспределить в пользу окружных апелляционных судов. Итак, апелляционных судов предложено создать 5, а кассационных - 9. Для их работы потребуются 170 судей в апелляцию и 790 в кассацию. Суды будут созданы в округах, но будут иметь межрегиональный характер.

В арбитражной системе кассационные суды действуют давно и хорошо себя зарекомендовали. Следовало бы только предусмотреть, чтобы кассационный арбитражный суд и аналогичного уровня суд общей юрисдикции не располагались в одном городе. Что касается создания апелляционных округов, то данную идею нужно детально изучить с учётом опыта других стран и возможных бюджетных расходов на их организацию. Вопрос о необходимости создания экстерриториальных инстанций в системе общей юрисдикции ставился экспертами с середины прошлого десятилетия. Можно полагать, что разрыв возможных связей между судами и региональными властями благотворно отразится на судебной системе в целом, позволит повысить независимость и качество судебных решений, сократить сроки рассмотрения дел, в том числе уголовных, а главное - поднять доверие общества к судебной системе как независимой ветви власти и сделать это можно быстро. Идея в принципе хорошая, главное, чтобы в окружные суды пришли судьи надлежащего уровня.

И наконец, рассмотрим вопрос об исследовании доказательств в суде апелляционной инстанции. Особенности исследования доказательств в суде второй инстанции определяются принципиальным положением о том, что апелляционное производство является не повторным рассмотрением дела в суде вышестоящей инстанции, а формой реализации контроля вышестоящего суда за соблюдением законности отправления правосудия нижестоящим судом. В этой связи видится важным, чтобы суд первой инстанции разъяснял сторонам их обязанность представить все доказатель- 
ства, имеющие, по их мнению, значение для правильного разрешения дела и исследования материалов в суде первой инстанции. Конечно, возможны и такие ситуации, когда стороны представляют суду апелляционной инстанции новые доказательства, которые не были ими представлены в суде первой инстанции, в том числе заявления ходатайств о вызове в судебное заседание новых свидетелей, экспертов, специалистов и других лиц, чьи показания или заключения не были предметом исследования в суде первой инстанции, или когда в материалах уголовного дела имелись доказательства, собранные на предварительном следствии, об исследовании которых стороны не заявили в суде первой инстанции, а при подаче апелляционной жалобы (представления), либо в ходе заседания суда апелляционной инстанции они заявляют ходатайство об исследовании таких доказательств непосредственно судом апелляционной инстанции. В суде апелляционной инстанции все перечисленные доказательства являются новыми, и поэтому представляется, что для суда, разрешающего ходатайство сторон об исследовании новых доказательств, важно сначала выяснить причины, по которым они не были представлены суду первой инстанции, и, уже исходя из установленных причин, принимать решение по заявленному ходатайству. К сожалению, ч. 6 ст. 389.13 УПК РФ специально не регламентирует порядок разрешения ходатайства об исследовании новых доказательств судом апелляционной инстанции, отсылая к порядку разрешения ходатайств в суде первой инстанции, установленному ст. 271 УПК РФ. Таким образом, создаются условия, при которых стороны могут злоупотреблять своими процессуальными правами, скрывая те или иные доказательства от суда первой инстанции для того, чтобы представить их непосредственно суду апелляционной инстанции и таким способом добиться отмены приговора или создать искусственные препятствия для рассмотрения дела в апелляционном порядке. 
Современный этап развития системы обжалования, проверки и пересмотра судебных решений характеризуется определённой несогласованностью научных исследований и нестабильностью законодательного регулирования. Вопросы полномочий, прав и обязанностей суда, прокуратуры, адвокатуры и других участников уголовного процесса в этой сфере раскрываются путём противостояния их деятельности друг другу. Поэтому одни авторы утверждают, что правовая система характеризуется нарушением баланса в сторону усиления карательных полномочий государства путём ущемления прав и свобод граждан, что требует предоставления дополнительных возможностей для защиты, другие вносят предложение расширить активность суда, прокуратуры в уголовном процессе [4].

В результате анализа затронутой темы можно прийти к следующим выводам. Идеального уголовного процесса никогда ни в одном государстве не было и не будет, что подтверждается наличием системы обжалования, проверки и пересмотра судебных решений, иначе её не было бы. Непрерывное, бесконечное изменение законодательства, предлагаемое большинством авторов научных работ в виде формулирования обязательных положений по изменению и (или) введению новых норм в УПК РФ, так же негативно может сказаться на судебной практике, как и несовершенство нормативных предписаний. Например, председатель Верховного суда РФ В.М. Лебедев неоднократно отмечал, что постоянное изменение законодательства негативно сказывается на правоприменительном процессе [5]. Поэтому необходимо искать новые подходы к рассмотрению проблем, возникающих при исследовании, в частности, апелляционной системы. Данную систему нельзя создать искусственно, она складывается исторически объективно и не может создаваться по желанию законодателей, представителей судейского, прокурорского, адвокатского или научного сообществ. Поэтому решение проблем состоит в том, чтобы не допустить несогласованности, что не исключает проведение реформирования УПК РФ, но 
не коренного, а обратить внимание на некоторые проблемные моменты. Должна присутствовать определённая согласованность научного, судейского и других сообществ, имеющих непосредственное отношение к уголовному процессу, по вопросам совершенствования законодательства на основе разработанных и обсуждаемых концепций, прежде чем вносить предложения по изменению в УПК РФ. Необходимо также ориентироваться на современные тенденции развития и реальное состояние правовой системы. И, учитывая проект последней судебной реформы в части создания окружных судов, думается, начало уже положено.

\section{Литература}

1. О внесении изменений в Уголовно-процессуальный кодекс Российской Федерации и признании утратившими силу отдельных законодательных актов (положений законодательных актов) Российской Федерации от 29.12.2010. № 433-Ф3: принят Гос. Думой Федер. Собр. Рос. Федерации 22.12.2010.: одобр. Советом Федерации Федер. Собр. Рос. Федерации 24.12.2010. // Российская газета. - 2010. - 31 декабря.

2. Уголовно-процессуальный кодекс Российской Федерации. От 18.12.2001. № 174-Ф3 (ред. от 30.03.2016.): принят Гос. Думой Федер. Собр. Рос. Федерации 22.11.2001.: одобр. Советом Федерации Федер. Собр. Рос. Федерации 05.12.2001.: введ. Федер. Законом Рос. Федерации от 18.12.2010. № 174-ФЗ // Собрание законодательства Российской Федерации. 2001. № 52 . Ч. 1. Ст. 4921. 4201.

3. Корня А., Чуракова О. У судов ломается вертикаль // Ведомости. - 2016. - №

4. Безмельницына Э.О. Прокурор в судах второй, кассационной и надзорной инстанций: Автореф. дис. ... канд. юрид. наук. Саратов, 2013. 31 с.; Сенькина Ж.С. Активность суда в уголовно-процессуальном доказывании: Автореф. дис. ... канд. юрид. наук. Нижний Новгород, 2014. 25 с.; Амельков Н.С. Оказание квалифицированной юридической помощи заявителю и свидетелю в уголовном судопроизводстве: Автореф. дис. ... канд. юрид. наук. М., 2014. - 33 с.

5. Текст: Борщевский М. (член Президиума Ассоциации юристов России) Вячеслав Лебедев: Не гражданин, а чиновник должен доказать в суде свою правоту // Российская газета. Федеральный выпуск. - 2013. - № 6011 (35).

6. Курченко В.Н. Важнейшие тенденции текущей судебной практики // Уголовный процесс. 2014. № 1. - 44 с.

7. Апелляция в уголовном судопроизводстве: научно-практическое пособие / Под общ. ред. В.В. Ершова. М.: Право, 2013. - 118 с.

8. Цели, функции и принципы российского уголовного судопроизводства (уголовно-процессуальная форма) / К.Б. Михайловская // М. - 2003.

9. О процессуальных функциях судебной власти и судов, ее осуществляющих / Проблемы теории и практики уголовного процесса, прокурорского надзора и правоохранительной деятельности в свете нового российского законодательства / Л.Ф. Мар- 
тыпяхин / Материалы научно-практической конференции (Томск. ТГУ. 29-31 января 2004 г.) / Под ред. М.К. Свиридова. // Томск. - 2004.

\section{References}

1. O vnesenii izmenenij v Ugolovno-processual'nyj kodeks Rossijskoj Federa-cii i priznanii utrativshimi silu otdel'nyh zakonodatel'nyh aktov (polozhenij zakonodatel'nyh aktov) Rossijskoj Federacii ot 29.12.2010. № 433-FZ: prinjat Gos. Dumoj Feder. Sobr. Ros. Federacii 22.12.2010.: odobr. Sovetom Federacii Feder. Sobr. Ros. Federacii 24.12.2010. // Rossijskaja gazeta. - 2010. - 31 dekabrja.

2. Ugolovno-processual'nyj kodeks Rossijskoj Federacii. Ot 18.12.2001. № 174-FZ (red. ot 30.03.2016.): prinjat Gos. Dumoj Feder. Sobr. Ros. Federacii 22.11.2001.: odobr. Sovetom Federacii Feder. Sobr. Ros. Federacii 05.12.2001.: vved. Feder. Za-konom Ros. Federacii ot 18.12.2010. № 174-FZ // Sobranie zakonodatel'stva Rossij-skoj Federacii. 2001. № 52 . Ch. 1. St. 4921.

3. Kornja A., Churakova O. U sudov lomaetsja vertikal' // Vedomosti. - 2016. - № 4201.

4. Bezmel'nicyna Je.O. Prokuror v sudah vtoroj, kassacionnoj i nadzornoj in-stancij: Avtoref. dis. ... kand. jurid. nauk. Saratov, 2013. 31 s.; Sen'kina Zh.S. Ak-tivnost' suda v ugolovno-processual'nom dokazyvanii: Avtoref. dis. ... kand. jurid. nauk. Nizhnij Novgorod, 2014. 25 s.; Amel'kov N.S. Okazanie kvalificirovannoj juridicheskoj pomoshhi zajavitelju i svidetelju v ugolovnom sudoproizvodstve: Avtoref. dis. ... kand. jurid. nauk. M., 2014. - 33 s.

5. Tekst: Borshhevskij M. (chlen Prezidiuma Associacii juristov Rossii) Vjacheslav Lebedev: Ne grazhdanin, a chinovnik dolzhen dokazat' v sude svoju pravotu // Rossijskaja gazeta. Federal'nyj vypusk. - 2013. - № 6011 (35).

6. Kurchenko V.N. Vazhnejshie tendencii tekushhej sudebnoj praktiki // Ugolovnyj process. 2014. № $1 .-44$ c.

7. Apelljacija v ugolovnom sudoproizvodstve: nauchno-prakticheskoe posobie / Pod obshh. red. V.V. Ershova. M.: Pravo, 2013. - 118 c.

8. Celi, funkcii i principy rossijskogo ugolovnogo sudoproizvodstva (ugolov-noprocessual'naja forma) / K.B. Mihajlovskaja // M. - 2003.

9. O processual'nyh funkcijah sudebnoj vlasti i sudov, ee osushhestvljajushhih / Problemy teorii i praktiki ugolovnogo processa, prokurorskogo nadzora i pravo-ohranitel'noj dejatel'nosti v svete novogo rossijskogo zakonodatel'stva / L.F. Mar-typjahin / Materialy nauchnoprakticheskoj konferencii (Tomsk. TGU. 29-31 janvarja 2004 g.) / Pod red. M.K. Sviridova. // Tomsk. - 2004. 